\title{
On Abilities and Training Strategies of University Journal Editors in the New Media Age
}

\author{
Lihua Zhao \\ Editorial Department of Journal of Jilin Agricultural University, Changchun 130118, China \\ Zhaolihua2004@126.com
}

Keywords: Editor; Ability; University journal; New media age; Training strategy

\begin{abstract}
The quality and ability of editors is one of the key factors that affect the quality of university journals. The new media age puts forward new and higher requirements for editors of university journals. Editors of university journals should have the following 10 abilities: planning ability, innovative ability, information acquirement and integration ability, learning ability, modern information technology application ability, scientific research ability, communicative ability, competitive ability, management ability, copyright protection ability. Universities and their editorial departments can promote the comprehensive ability of editors through the construction of learning-oriented editorial departments, the implementation of lifelong education, the improvement of assessment and incentive mechanism.
\end{abstract}

\section{Introduction}

University journals are important carriers of scientific research achievements in universities, and also an important platform and window for demonstrating academic level in universities. The quality of university journals directly affects the dissemination of academic research results and academic exchanges. The quality and ability of editors is one of the key factors that affect the quality of university journals. A high quality journal must have an editorial team with high quality and ability. With the rapid development of science and technology, the new media based on digital network has been born[1]. The arrival of the new media age has brought the opportunity for accelerating the development of university journals, and put forward severe challenges. Competition among sci-tech journals is more fierce. The survival and development of university journals have been greatly impacted, and the ability of university journal editors needs to be developed and improved. How to train and promote the ability of university journal editors is an important topic for editors of university journals in the new age.

\section{Abilities of University Journal Editors in the New Media Age}

Planning Ability. Planning ability is the ability of editors to design and operate the publishing process in an all-round way. It is a comprehensive expression of the editing ability, the selection of periodical papers and column design etc. Planning ability is the essential ability of university journal editors in the new age. In the new media age, abundant information resources and their characteristics of instance, multi-dimenstionality and interactivity provide favorable conditions for editing and planning. Meanwhile, higher requirements have been put forward for editors of university journals [2]. University journals are a comprehensive academic periodical, therefore, editors of university journals have more questions to think about than editors of general academic journals. They should consider not only the column design, the quantity and the length of each paper, but also the balance of the disciplines and specialties, and also the characteristics and advantages of the universities, the majors and the key subjects [3]. This requires the editors of journals to have excellent planning ability. According to the scientific research condition of university and the purpose of journals, with their own academic sensitivity and academic judgment, combined with the latest academic trends at home and abroad, the editors can screen, synthesize and refine the relevant research information and research results, and put forward valuable and 
high-quality topics, so as to make the journals vigorous and distinctive, thus forming their own brands.

Innovative Ability. In the new age of mass entrepreneurship and innovation, the cultivation of innovative spirit has become the soul of higher education [4]. Innovation is the motive force of the development of university journals, and the innovative ability is the most important quality for editors. In the new media age, the channels for people to obtain scientific and technological information have undergone major changes. The survival and development of university journals are facing severe challenges. How to change the traditional idea and method of running journals and to explore the running model of university journals in the new age is an important problem that the editors of university journals are to deal with. Therefore, if the university journals want to seize the opportunity in the new media age and stand out in many publications, they must make great efforts in innovation. As editors of university journals, they must have outstanding innovative ability and thinking. In the selection of topics, the editors should reveal forward-looking and innovative topics from their own unique perspectives, and build their own features and brands to achieve "the existent out of the nonexistent; the excellent out of the existent; the extraordinary out of the excellent; the neoteric out of the extraordinary!'[2] to remain invincible in the fierce market .

Information Acquirement and Integration Ability. Modern society has entered the information age, with the rapid development of science and technology, the means of information communication is changing with each passing day. Information is the basis of selecting topics and organizing manuscripts. Information awareness is the basis and prerequisite for journal editors to identify and use high quality scientific and technical information, the capital and guarantee of continuous innovation and development of university journals and the necessary quality of university journal editors [5]. In the new media age, editors of university journals should not only enhance their information awareness, but also have a stronger ability to acquire and integrate information. It is the ability of editors to cultivate, develop, capture, transform and utilize information and change the inherent information environment in the long-term editing practice [6].

Learning Ability. Modern society is in a rapidly changing information age and science and technology are developing rapidly. New disciplines and interdisciplinary fields are increasing. New knowledge, new concepts, new theories, new technologies and new fields emerge one after another, and the speed of knowledge updating is becoming faster and faster [7-8]. This requires editors to keep pace with the times, to improve their ability to learn independently and to continue to learn so as to replenish, update and optimize the knowledge structure in time. At present, learning has become a very important and urgent task in the implementation of talent strategy in modern publishing industry [9]. As university journals report mainly on the teaching and research results of various subjects in universities and colleges. Moreover, there is a large span between some disciplines. Journal editing business involves a wide range of knowledge, which requires editors to have stronger learning ability. In the new media age, editors should also enhance the sense of responsibility, mission, crisis and urgency of learning [3].

Modern Information Technology Application Ability. Computer, network, multimedia and other modern information technology impact on the development of university journals more and more deeply. This not only brings opportunities and challenges to the development of university journals, but also puts forward new and higher requirements for journal editors, which is an unprecedented test for editors. Moreover, this kind of test becomes urgent with the development of information technology, which requires that journal editors not only have the quality and ability in the traditional sense, but also learn modern editing theory and techniques so as to improve the modern information technology application ability continuously. Therefore, editors of university journals must renew their thinking, change their concepts, enhance their sense of the times and urgency, foster modern editing consciousness and enhance their ability to accept new things [6].

Scientific Research Ability. Editors of university journals should have certain scientific research ability, which is the requirement for a review, identification and selection of manuscripts [4]. This is because university journals are more professional and the content of the editing work includes reading, modification and processing of academic papers. Its essence is to carry out 
academic dialogue with the author on the subject of his research [10]. Only when the editors have certain academic level and strong scientific research ability can they carry out deep processing of the authors' academic papers. Therefore, editors should enhance their scientific research ability in the new media age. Editors of university journals have unique research environment and conditions so they can improve their scientific research ability by participating in scientific research. Moreover, combining scientific research with their own work editors can also deeply understand the development of professional knowledge and discipline, which helps to raise the perceptual experiences accumulated to rational knowledge so as to guide and promote the editing work better [11].

Communicative Ability. Communicative ability is not only the basic quality of editors, but also an important index to measure the quality of modern editors. Communicative ability directly or indirectly affects the information capture, the selection of topics, the authors' choice, the quality of manuscripts, the search for reviewers and even the effect of the publication of the whole journal $[4,7,12]$ because the editing work from the selection of topics, planning, organization, submitted manuscripts, editing, cover design, graphic printing, publishing, information feedback and other aspects are not done by one person, which must be cooperated with the relevant units and related personnel. Throughout the process, editors are dealing with people, and they need to communicate and coordinate with others patiently and carefully. If editors don't have a certain communicative ability, the editorial work can not be carried out smoothly, and it is impossible to compile high-quality journals $[3,8]$.

Competitive Ability. In the new era, the competition of publishing industry is becoming more and more fierce. This kind of competition is not a kind of extensive competition that combines resources and consumption, but is more harmonious and more intelligent [9]. Journals are faced with competition from many aspects of society: domestic and international competition, peer competition, competition within journals. The competition of university journals is further intensified from the selection of topics, to manuscript organization, to publication and to distribution. Therefore, it is a new requirement for editors to strengthen the consciousness of competition and cultivate the competitive ability. In the new media age, the competitive ability of editors means that they have the ability to cope with change and fierce competition and to win in the competition [13-14]. To meet the needs of the situation, editors of university journals must renew their ideas and have a sense of crisis, a sense of urgency and a keen sense of market competition. They should actively explore new models and methods with keen insight, and constantly improve their competitiveness in practice.

Management Ability. Management ability is the ability of editors' career development and promotion. In the new media age, sci-tech journals are faced with a severe competitiveness and how to manage is a problem that university journals must seriously consider and can not be avoided in the new age. Therefore, editors should have management ability, which is the necessary condition to ensure the vitality of journals. Only when journal editors have a strong management ability can the authors and readers be enlarged so that the journals can really move towards the market to survive and develop in the fierce competition. Journals can create economic benefits on the premise of realizing social benefits[4,15]. Therefore, editors of university journals should set up management consciousness, strengthen market concept and learn marketing and management knowledge.

Copyright Protection Ability. In the new media age, people's legal awareness, copyright awareness and the awareness of safeguarding rights have gradually increased[16]. The editing work is closely related to the law and the legal and policy literacy is indispensable to the journal editors [4]. Learning legal knowledge, enhancing copyright consciousness and improving copyright protection ability are important requirements for editors in the new age. In the new media age, information has become the most important resource and competition for scientific and technological information has become more intense. Scientific and technological information can only produce real benefits when it is transmitted legally and orderly. 


\section{Strategies for Training Comprehensive Ability of University Journal Editors}

Establishing the Concept of Lifelong Learning and Building a Learning-oriented Editorial Department. In order to improve the quality and ability of editors, they must establish the concept of lifelong learning and build a learning-oriented editorial department. Building a learning-oriented editorial department can stimulate the learning enthusiasm of editors, arouse the interest of editors, and train more excellent editors [12,17]. The editorial department can create a good learning environment and a strong learning atmosphere for the editors by providing learning places and learning materials, improving learning systems and innovating learning methods. Establishing long-term competitive learning mechanism can make the editors learn to compete with each other and promote each other. This kind of learning atmosphere of editorial departments will stimulate the vitality of editors, tap the potential of editors, improve the quality of editors and promote the healthy growth of editors. Learning methods can be various such as massed learning in the periodical press, distributed learning in the editorial department, self-learning of editors, seminars on thematic learning, reports made by experts and scholars, writing reading notes and exchanging learning experiences etc.

Constructing Reasonable Talent Knowledge Structure and Carrying out Further Education. At present, the professional knowledge structure of university journal editors is unreasonable, their educational background is low and the aging of talents is serious. Especially, the compound talents with strong comprehensive ability are in short supply [11-12]. Therefore, reasonable knowledge structure of talents should be constructed and further education should be carried out. Universities and their editorial departments should create opportunities for the further education of editors and provide necessary economic and policy support. Editors should receive business training on the regular basis. Editors are encouraged to participate in academic exchanges. Editors are encouraged to pursuit a degree while being on their post. Editors are encouraged to carry out academic research.

Establishing a Competitive Mechanism. Improving the assessment system: The establishment of a reasonable competitive mechanism is an essential measure for editing personnel training. The cultivation of editing talents can not be separated from the motivation. The retention and introduction of talents need the means of motivation. Motivation can maximize human potential and accelerate the growth of talents. First of all, the post responsibility system should be established and the competition mechanism should be introduced in terms of post promotion, academic title evaluation, projects declared, performance income distribution and other aspects. Secondly, incentives should be innovated and improved. Motivation should be a combination of material reward and spiritual encouragement. Spiritual encouragement, caring, trust and being put in an important position are often seen more important by editors; encouragement should be combined with rewards and punishments, giving priority to reward. In order to fully exploit the potential of editors, to arouse and protect the enthusiasm, initiative and creativity of editors, and to maximize the role of competition incentive mechanism in promoting editorial ability $[12,18]$.

\section{References}

[1] M. Zhang and J. Feng: Characteristics of the New Media Age and Its Influence on China [J]. West Leather, ( 2016) No 4, p.114. (in Chinese).

[2] Y. Song: On the Basic Qualities and Abilities of Modern Editors [J]. Journal of Hunan First Normal University, Vol. 9 (2009) No.3, p. 161-163. (in Chinese).

[3] F.H. Hou, L. Huang, J.Yan and Y. Zhao: Professional characteristics and quality requirements of journal editors in the universities [J]. ACTA EDITOLOGICA, Vol.24 (2012) No.(Sup.1), p. 87-88. (in Chinese).

[4] J.H. Zhu: Quality and Capability the Editors Should Possess in Modern Journals of Colleges [J]. JOURNAL OF NINGBO UNIVE RS ITY (NSEE), Vol.17 (2004) No.2, p.236-239. (in Chinese). 
[5] X.J. Song: On the Qualities that Editors of Modern Sci-tech Journals Should Possess [J]. Journal of Kashgar Teachers College, Vol. 24 (2003) No. 5, p.102-104. (in Chinese).

[6] R.J. Yang: On Improvement of the of Editors' Quality of Journal in the Era of Network Digitalization [J]. Journal of Suzhou University of Science and Technology (Social Science Edition), Vol.27 (2010) No.6, p.94-96. (in Chinese).

[7] Y.F. Qin: Consciousness and Ability of Modern University Journal Editors [J]. JOURNAL OF HEILONGJIANG INSTITUTE OF SOCIALISM, (2014) No.2, p.52-55. (in Chinese).

[8] M. Xing: Qualities that Editors of Modern Academic Journals Should Possess[J]. Study on China Administration for Industry \& Commerce, (2005) No.5, p. 74-76. (in Chinese).

[9] L.C. Chang: New Exploration of Editorial Personnel Training Mode in the Era of Mass Media [J]. Journal of Tibet Nationalities Institute (Philosophy and Social Sciences), Vol. 30 (2009) No. 4, p.101-104. (in Chinese).

[10] Y.T. Han and T.W. Chang: Quality of journal editors in the colleges and universities and ways of improvement [J]. ACTA EDITOLOGICA, Vol. 14 (2002) No. 1, p. 67-69. (in Chinese).

[11] Y.L. Sheng: Discussion on qualities of the editors in colleges and universities [J].Journal of Changsha Telecommunications and Technology Vocational College, Vol. 8 (2009) No. 4, p. 86-89. (in Chinese).

[12] S.X. Xie, H. Yang and J. Gao: Qualities and Training Methods of Compound Editors in Military Sci-tech Periodicals [J]. Journal of Huanggang Normal University, Vol.31 (2011) No. 3, p.188-190. (in Chinese).

[13] M.Z. Pan: Quality and Ability of Compound Editors of Medical Sci-tech Periodicals in the New Era [J]. CHINESE JOURNAL OF SCIENTIFIC AND TECHNICAL PERIODICALS, Vol. 22 (2011) No. 2, p. 287-290. (in Chinese).

[14]B.J. Zhang: Discussion on Qualities that Modern Periodical Editors Should Possess[J]. BRAND, (2009) No. 1, p. 56. (in Chinese).

[15] S.Y. Ma and S.M. Song: Several Qualities that Editors of Modern Sci-tech Periodicals Should Possess [J]. TIANJIN SCIENCE \& TECHNOLOGY, (2007) No. 6, p. 64-65. (in Chinese).

[16] Y.N. Jin: New Requirements for Quality of College Journal Editors in the Information Age [J]. CHUANBO YU BANQUAN, (2016) No. 2, p. 47-49. (in Chinese).

[17] Y. Zheng: On Qualities of the Editors and the Ways to Improvement Their Qualities in Colleges and Universities [J]. Journal of Inner Mongolia University for Nationalities (Social Science Edition), Vol. 39 (2013) No. 6, p. 106-108. (in Chinese).

[18] J.H. Wang and F. Wang: Discussion on the Culture Mechanism of Editing Personnel of Scientific Periodicals [J]. Journal of Library and Information Sciences in Agriculture, Vol.18 (2006) No. 5, p.119-121. (in Chinese). 